\title{
Catalytic Behaviour of Mesoporous Cobalt-Aluminum Oxides for CO Oxidation
}

\author{
Ankur Bordoloi, ${ }^{1}$ Miguel Sanchez, ${ }^{2}$ Heshmat Noei, ${ }^{3}$ Stefan Kaluza, ${ }^{4}$ Dennis Großmann, ${ }^{5}$ \\ Yuemin Wang, ${ }^{5}$ Wolfgang Grünert, ${ }^{5}$ and Martin Muhler $^{5}$ \\ ${ }^{1}$ CSIR-Indian Institute of Petroleum, Dehradun, India \\ ${ }^{2}$ Instituto de Física del Sur (UNS-CONICET), 8000 Bahía Blanca, Argentina \\ ${ }^{3}$ Research Group X-Ray Physics and Nanoscience Deutsches Elektronen-Synchrotron DESY, Hamburg, Germany \\ ${ }^{4}$ Fraunhofer Institute of Environmental, Safety, and Energy Technology UMSICHT, Oberhausen, Germany \\ ${ }^{5}$ Laboratory of Industrial Chemistry, Ruhr University Bochum, Bochum, Germany \\ Correspondence should be addressed to Ankur Bordoloi; ankurankurbordoloi734@gmail.com
}

Received 12 May 2014; Revised 31 August 2014; Accepted 1 September 2014; Published 1 October 2014

Academic Editor: Mohammed M. Bettahar

Copyright (c) 2014 Ankur Bordoloi et al. This is an open access article distributed under the Creative Commons Attribution License, which permits unrestricted use, distribution, and reproduction in any medium, provided the original work is properly cited.

\begin{abstract}
Ordered mesoporous materials are promising catalyst supports due to their uniform pore size distribution, high specific surface area and pore volume, tunable pore sizes, and long-range ordering of the pore packing. The evaporation-induced self-assembly (EISA) process was applied to synthesize mesoporous mixed oxides, which consist of cobalt ions highly dispersed in an alumina matrix. The characterization of the mesoporous mixed cobalt-aluminum oxides with cobalt loadings in the range from 5 to $15 \mathrm{wt} \%$ and calcination temperatures of 673,973 , and $1073 \mathrm{~K}$ indicates that $\mathrm{Co}^{2+}$ is homogeneously distributed in the mesoporous alumina matrix. As a function of the Co loading, different phases are present comprising poorly crystalline alumina and mixed cobalt aluminum oxides of the spinel type. The mixed cobalt-aluminum oxides were applied as catalysts in CO oxidation and turned out to be highly active.
\end{abstract}

\section{Introduction}

Supported metal oxide catalysts have attracted much attention in recent years due to their widespread applicability in industrially and academically important reactions. The extent and nature of the interaction, dispersion, and reducibility of the metal oxides depend on the synthesis method, loading, calcination temperature, and time. Cobalt supported on alumina is a typical catalyst, which is specially important for Fischer-Tropsch synthesis. Conventionally, the preparation of cobalt catalysts is performed by incipient wetness impregnation using suitable cobalt precursors on commercial alumina at low $\mathrm{pH}$. Weak interaction is normally observed between the positively charged alumina carrier and the cobalt cations resulting in relatively large crystallite sizes [1-4]. Continuous efforts have been made in the last few decades by several groups [5-7] to synthesize porous alumina with high surface area by high-temperature dehydration of bulk powders [8], modified sol-gel synthesis in the presence of organic moieties [9, 10], different surfactants [3], block copolymers [11-14], or evaporation-induced self-assembly (EISA) with colloidal precursors and amine structural agents $[15,16]$. These materials represent an active support, which may participate positively or negatively in the formation of the final catalysts. Moreover, the methods of hard templating [17] (carbon template) and microwave irradiation [18] in the presence of surfactants have been applied to synthesize alumina materials with crystalline, ordered, and uniform mesopores. However, this process is very time consuming and hardly scalable for industrial applications.

Ordered mesoporous materials are promising catalyst supports due to their favourable structural characteristics [11]. The presence of surface hydroxyl groups offers the opportunity to support metals and metal oxides with catalytic activity. Moreover, due to the large pores they provide less diffusion limitation for the reactants and products. Transition 
aluminas are mainly used as either catalysts or catalyst supports in various industrially relevant processes. Traditional alumina supports are nonporous or show disordered structures with wide pore-size distributions, which makes it difficult to differentiate which pores are involved in the reaction. After the discovery of well-ordered, periodically organized mesoporous silica materials (M41S family, Mobil [19]), extensive efforts have been made to extend the group of mesoporous materials to alumina systems [20].

The evaporation-induced self-assembly (EISA) process is a highly suitable approach to design functional mesoporous oxides with fine-tuned structural, compositional, and morphological properties [21]. The EISA technique can be considered liquid crystal template strategy. In this process, a homogeneous precursor solution is dispersed into fine droplets and subsequently dried and calcined, which results in the formation of mesostructured materials. The present contribution describes an improved synthesis methodology of mesoporous mixed cobalt-aluminum oxides with various cobalt loadings using the EISA process. The materials were thoroughly characterized by nitrogen physisorption, $\mathrm{X}$ ray diffraction (XRD), transmission and scanning electron microscopy (TEM, SEM), X-ray photoelectron spectroscopy (XPS), and ultra-high vacuum Fourier transformed infrared spectroscopy (UHV-FTIR) using CO as probe molecule. As a first catalytic test reaction to monitor the redox properties, the mixed metal oxides were applied in $\mathrm{CO}$ oxidation.

\section{Experimental}

2.1. Synthesis. All solvents and chemicals were obtained from Aldrich Chemicals and used as received. The required amounts of cobalt nitrate and $6.0 \mathrm{~g}$ of (EO)20(PO)70(EO)20 triblock copolymer (Pluronic P123) were dissolved in $100 \mathrm{~mL}$ of ethanol. Additionally, $12 \mathrm{~g}$ of aluminium isopropoxide was dissolved in $10 \mathrm{~mL}$ of nitric acid $(68 \%)$ and $100 \mathrm{~mL}$ of ethanol. Once dissolved, the two solutions were combined and allowed to stir for $5 \mathrm{~h}$. The obtained materials were dried and calcined at the desired temperatures in a calcination furnace applying a heating rate of $2 \mathrm{~K} / \mathrm{min}$ and holding the final temperature for $6 \mathrm{~h}$. The obtained catalysts were denoted as $x \mathrm{Co}-\mathrm{Al}_{2} \mathrm{O}_{3}$, where $x$ is the Co loading in wt\%.

2.2. Characterization. The prepared catalysts and the support were characterized by $\mathrm{N}_{2}$ physisorption measurements at $77 \mathrm{~K}$ using a slightly modified Autosorb 1C setup (Quantachrome). Prior to the measurements, the samples were degassed under vacuum for $2 \mathrm{~h}$ at $473 \mathrm{~K}$. The specific surface areas were determined from the adsorption isotherms in the relative pressure $\left(p / p_{0}\right)$ range from 0.06 to 0.20 applying the BET method. The pore-size distributions (PSDs) were calculated from the nitrogen desorption branch using the Barrett-Joyner-Halenda (BJH) method considering the maximum of the PSD as the average pore size. The pore volume was considered as the volume of liquid nitrogen adsorbed at $p / p_{0} \sim 1$.

XRD patterns were recorded in the $2 \theta$ range from 0.5 to $5^{\circ}$ using D8-Advance-Bruker-AXS diffractometer and 10 to $70^{\circ}$ (step width of $0.0308^{\circ}$ ) with a Panalytical MPD diffractometer using $\mathrm{Cu} \mathrm{K}_{\alpha}$ radiation $(\lambda=1.5418 \AA)$ at $45 \mathrm{kV}$ and $40 \mathrm{~mA}$, 0.58 divergent and antiscatter slits, a $0.2 \mathrm{~mm}$ high receiving slit, incident and diffracted beam 0.04 rad soller slits, and a secondary graphite monochromator. Powder diffraction files (PDFs) from the International Centre of Diffraction Data (ICDD) combined with the X'Pert Line software (Panalytical, Almeno) were used for qualitative phase analysis.

TEM analysis was carried out using a Hitachi H-8100 transmission electron microscope $\left(200 \mathrm{kV}, \mathrm{LaB}_{6}\right.$ filament). The samples were prepared by dispersing the powder material in isopropanol and putting a drop of the solution on a carboncoated $\mathrm{Cu}$ grid. SEM measurements of the powder materials were performed with a high-resolution thermally aided field SEM (Zeiss, LEO1530 Gemini).

$\mathrm{X}$-ray photoelectron spectroscopy (XPS) measurements were carried out in an ultra-high vacuum (UHV) setup equipped with a monochromatic $\mathrm{Al} \mathrm{K} \mathrm{K}_{\alpha} \mathrm{X}$-ray source $(\mathrm{h} \nu=$ $1486.6 \mathrm{eV}$ ) operated at $14.5 \mathrm{kV}$ and $35 \mathrm{~mA}$ and a highresolution Gammadata-Scienta SES 2002 analyzer. The base pressure in the measurement chamber was maintained at about $7 \times 10^{-10}$ mbar. The measurements were carried out in the fixed transmission mode with a pass energy of $200 \mathrm{eV}$ resulting in an overall energy resolution better than $0.5 \mathrm{eV}$. A flood gun was applied to compensate the charging effects. High-resolution $\mathrm{C} 1 \mathrm{~s}, \mathrm{O} 1 \mathrm{~s}, \mathrm{Al} 2 \mathrm{p}$, and Co $2 \mathrm{p}$ spectra were recorded. The binding energy scales were recalibrated based on the $\mathrm{C}$ 1s line from adventitious hydrocarbons at $284.8 \mathrm{eV}$. The Casa XPS software [22] with a 70:30 GaussianLorentzian product function and Shirley background subtraction was used for peak deconvolution. The Co $2 \mathrm{p}$ spectra were normalized to the corresponding $\mathrm{Al} 2 \mathrm{p}$ peak areas for better comparison.

In addition, the interaction of $\mathrm{CO}$ with $\mathrm{Al}_{2} \mathrm{O}_{3}$ and $\mathrm{Co}-\mathrm{Al}_{2} \mathrm{O}_{3}$ nanoparticles was investigated employing UHVFTIR spectroscopy. CO was used to probe the comparable substrates in order to get more information on the local structure of $\mathrm{CO}$ adsorbed on $\mathrm{Al}_{2} \mathrm{O}_{3}$ and $\mathrm{Co}-\mathrm{Al}_{2} \mathrm{O}_{3}$ surfaces using a novel UHV apparatus combining a state-of-the-art vacuum IR spectrometer (Bruker, VERTEX 80v) with an UHV system (Prevac) $[23,24]$. Pure alumina and mixed $\mathrm{Co}-\mathrm{Al}$ oxide powder samples were first pressed on a goldcoated stainless steel grid and then mounted on a sample holder that was specially designed for the FTIR transmission measurements under UHV conditions. The base pressure in the measurement chamber was $2 \times 10^{-10} \mathrm{mbar}$. The optical path inside the IR spectrometer and the space between the spectrometer and UHV chamber were also evacuated to avoid atmospheric moisture adsorption resulting in high sensitivity and stability. The samples were cleaned in the UHV chamber by heating to $850 \mathrm{~K}$ in order to remove adsorbed species (e.g., carbonate and hydroxyl groups) [24]. Prior to each exposure, the spectrum of clean powder was used as a background reference. All UHV-FTIR spectra were collected with 1024 scans at a resolution of $4 \mathrm{~cm}^{-1}$ in the transmission mode.

2.3. Catalytic Testing. $\mathrm{CO}$ oxidation was performed in a glass-lined fixed-bed microreactor with an inner diameter of $4 \mathrm{~mm}$ coupled to a gas supply equipped with mass-flow controllers. Gases were obtained by Air Liquide with the 
TABLE 1: $\mathrm{N}_{2}$ physisorption results obtained with the $\mathrm{Co}-\mathrm{Al}_{2} \mathrm{O}_{3}$ oxides.

\begin{tabular}{lccc}
\hline Sample & Surface area $/ \mathrm{m}^{2} \mathrm{~g}^{-1}$ & Pore diameter $/ \mathrm{nm}$ & Pore volume $/ \mathrm{cm}^{3} \mathrm{~g}^{-1}$ \\
\hline $\mathrm{Al}_{2} \mathrm{O}_{3}$ & 300 & 6.8 & 0.70 \\
$5 \mathrm{Co} / \mathrm{Al}_{2} \mathrm{O}_{3}(973)$ & 287 & 8.8 & 0.82 \\
$10 \mathrm{Co} / \mathrm{Al}_{2} \mathrm{O}_{3}(973)$ & 258 & 7.7 & 0.74 \\
$15 \mathrm{Co} / \mathrm{Al}_{2} \mathrm{O}_{3}(973)$ & 258 & 5.6 & 0.66 \\
$5 \mathrm{Co} / \mathrm{Al}_{2} \mathrm{O}_{3}(673)$ & 275 & 8.8 & 0.78 \\
$5 \mathrm{Co} / \mathrm{Al}_{2} \mathrm{O}_{3}(1073)$ & 284 & 6.6 & 0.62 \\
\hline
\end{tabular}

$x \mathrm{Co}-\mathrm{Al}_{2} \mathrm{O}_{3}(y)=$ cobalt loading (wt $\left.\%\right)$ in $\mathrm{Al}_{2} \mathrm{O}_{3}$ (calcination temperature, $\mathrm{K}$ ).

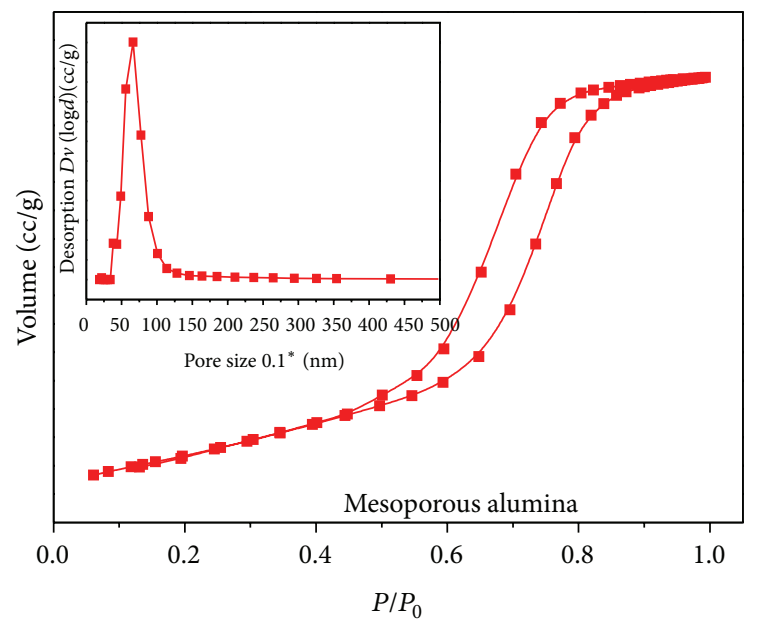

(a)

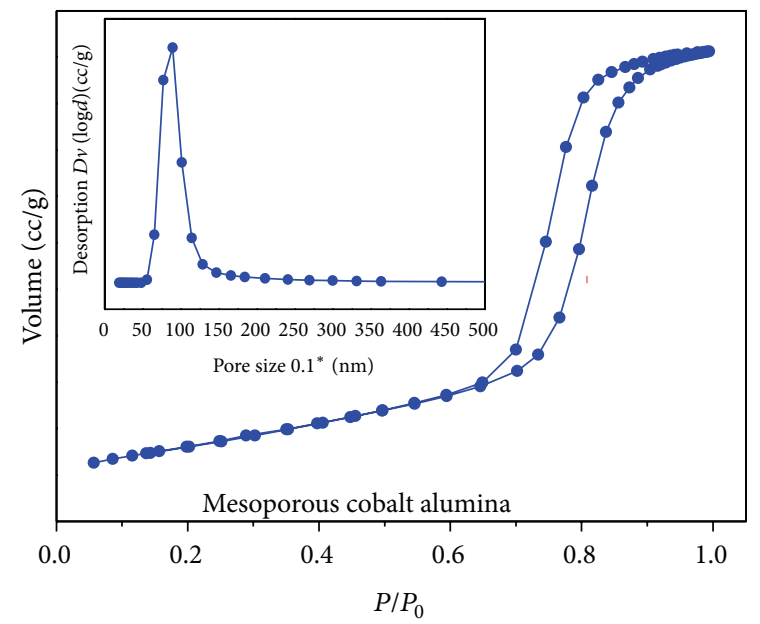

(b)

FIgURE 1: $\mathrm{N}_{2}$ physisorption isotherms of (a) pure $\mathrm{Al}_{2} \mathrm{O}_{3}$ and (b) $5 \mathrm{Co}-\mathrm{Al}_{2} \mathrm{O}_{3}$; the corresponding pore size distributions (BJH method) are shown in the insets.

following purities: $1.97 \% \mathrm{H}_{2}$ (99.9999\%) in $\mathrm{He}(99.9999 \%)$, $1 \% \mathrm{CO}(99.997 \%)$, and $20 \% \mathrm{O}_{2}(99.995 \%)$ in $\mathrm{He}(99.999 \%)$, as well as pure $\mathrm{He}$ (99.9999\%). The reactor was filled with 100 $\mathrm{mg}$ of the samples in the sieve fraction of $250-350 \mu \mathrm{m}$. Prior to the reaction, the catalysts were reduced with $1.97 \% \mathrm{H}_{2}$ at $573 \mathrm{~K}$. After cooling to room temperature, a flow of $1 \% \mathrm{CO}$ and $20 \% \mathrm{O}_{2}$ in $\mathrm{He}$ was applied $\left(55 \mathrm{Nml} \mathrm{min}^{-1}\right)$ increasing the temperature with $5 \mathrm{~K} \mathrm{~min}^{-1}$ up to $573 \mathrm{~K}$. The concentrations of $\mathrm{CO}$ and $\mathrm{CO}_{2}$ at the gas outlet were continuously detected by a nondispersive infrared analyzer, while the $\mathrm{O}_{2}$ concentration was measured with a paramagnetic sensor analyzer (XSTREAM, Emerson).

\section{Results and Discussion}

The obtained mixed oxides were investigated by $\mathrm{N}_{2}$ physisorption. The resulting isotherms for the $\mathrm{Al}_{2} \mathrm{O}_{3}$ and the mesoporous $\mathrm{Co}-\mathrm{Al}_{2} \mathrm{O}_{3}$ oxides were found to be type IV isotherms with $\mathrm{H} 1$ hysteresis loop with a sharp increase in the amount of nitrogen adsorbed at a relative pressure $\left(p / p_{0}\right)$ of about $0.6-0.9$. The shape of the isotherm confirms the mesoporosity of $\mathrm{Al}_{2} \mathrm{O}_{3}$ (Figure 1(a)) [11]. Moreover, even after the addition of cobalt (Figure 1(b)) the textural properties of $\mathrm{Al}_{2} \mathrm{O}_{3}$ were maintained. The pure $\mathrm{Al}_{2} \mathrm{O}_{3}$ sample exhibited a maximum pore diameter of about $6.8 \mathrm{~nm}$ and a specific surface area of $300 \mathrm{~m}^{2} \mathrm{~g}^{-1}$ (Table 1). Adding more cobalt during the synthesis changed the pore size from 8.8 to $5.6 \mathrm{~nm}$. The decrease in pore size could be due to formation cobalt oxide in the pores in case of higher loading and led to a slight decrease of the specific surface area.

The TEM images of the mixed $\mathrm{Co}-\mathrm{Al}_{2} \mathrm{O}_{3}$ samples (Figure 2) also provide strong evidence that the hexagonally ordered mesoporous structure of $\mathrm{Al}_{2} \mathrm{O}_{3}$ is maintained. The pore diameters estimated from the micrographs were found to be $8-9 \mathrm{~nm}$, which is in good agreement with the physisorption results.

The bulk structure of the $\mathrm{Co}-\mathrm{Al}_{2} \mathrm{O}_{3}$ samples was investigated by powder X-ray diffraction. The low angle XRD measurements (Figure 3 ) reveal a peak in the range between 0.5 and $5^{\circ}$ which is in good agreement with the TEM image of the hexagonally ordered material. The XRD patterns show the presence of X-ray amorphous alumina and the formation of a crystalline spinel phase in the samples with higher Co loadings (Figure 4(a)) and higher calcination temperatures (Figure 4(b)), which is in good agreement with the results reported in the literature [25]. It is not possible to differentiate between $\mathrm{Co}_{3} \mathrm{O}_{4}$ and a mixed $\mathrm{CoAl}_{2} \mathrm{O}_{4}$ phase, because both phases crystallize in the cubic spinel structure $(F d 3 m)$ and the ionic radii of $\mathrm{Co}^{3+}$ and $\mathrm{Al}^{3+}$ are nearly of the same value. 


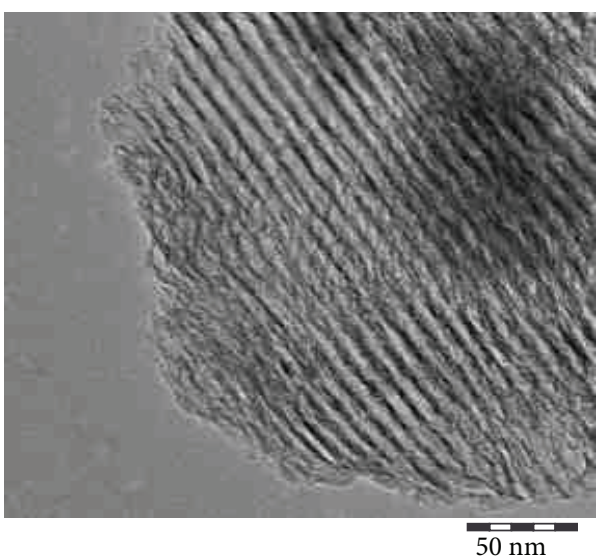

(a)

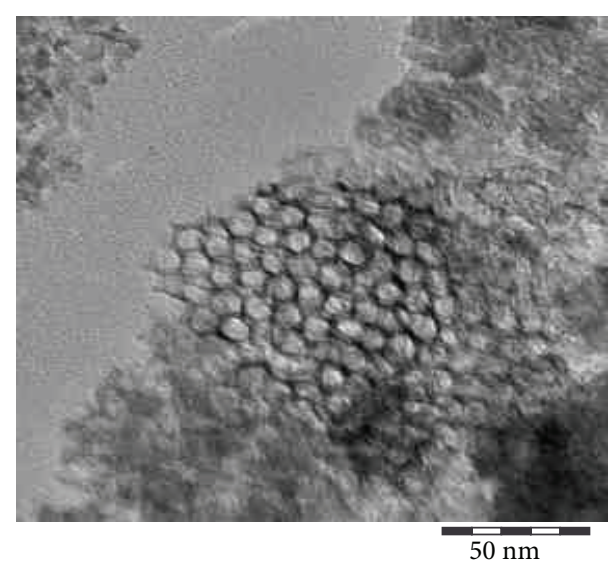

(b)

Figure 2: TEM images of the $5 \mathrm{Co}-\mathrm{Al}_{2} \mathrm{O}_{3}$ oxide calcined at $973 \mathrm{~K}$.

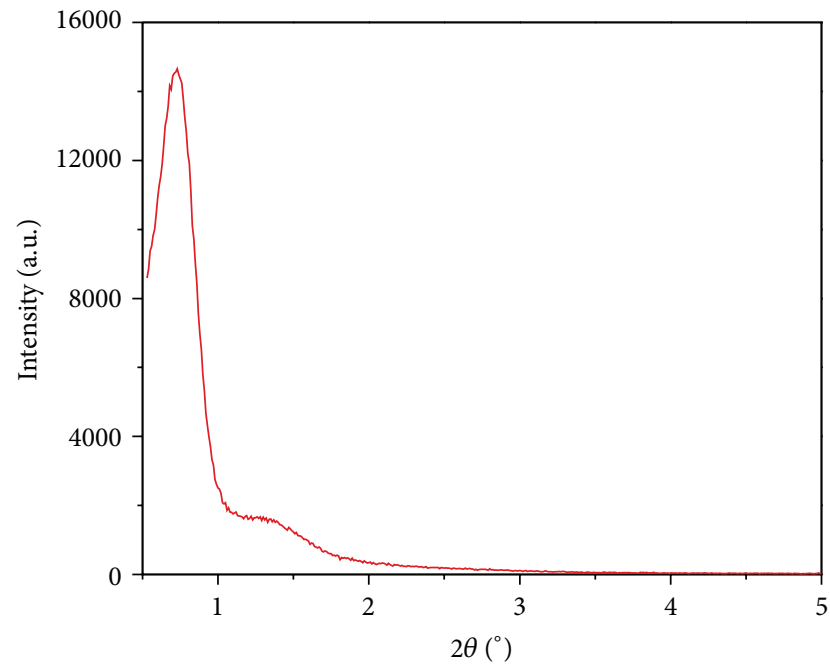

Figure 3: Low angle XRD of the $5 \mathrm{Co}-\mathrm{Al}_{2} \mathrm{O}_{3}$ oxide calcined at $973 \mathrm{~K}$.

The morphology of the materials was further investigated by means of SEM. The micrograph of one $\mathrm{Co}-\mathrm{Al}_{2} \mathrm{O}_{3}$ sample is shown in Figure 5(a). It indicates that the mixed Co- $\mathrm{Al}_{2} \mathrm{O}_{3}$ oxides consist of irregularly shaped agglomerates exhibiting a sponge-like structure. The homogeneous distribution of Co inside the alumina matrix is demonstrated by elemental mapping (Figure 5(b)).

Samples with different Co loadings and different calcination temperatures were analyzed by means of XPS. The Co $2 \mathrm{p}$ spectra of three mixed oxides with different Co loadings $(5,10$, and $15 \mathrm{wt} \%)$ calcined ex situ at $973 \mathrm{~K}$ are shown in Figure 6. All spectra exhibit the same features consisting of the two main Co $2 \mathrm{p}_{3 / 2}$ and $2 \mathrm{p}_{1 / 2}$ peaks and two pronounced satellites at their high-energy side designated as satl and sat 2 . It is known that the occurrence of satellites is related to the shake-up process of $\mathrm{Co}^{2+}$ ions in a high-spin configuration, which is the case for $\mathrm{Co}-\mathrm{Al}_{2} \mathrm{O}_{3}$ [26]. The analysis of the peak energies results in a shake-up splitting of $4.9 \mathrm{eV}$ for satl and a $\mathrm{Co} 2 \mathrm{p}_{3 / 2}$ binding energy of $781.4 \mathrm{eV}$ that is in good agreement
TABle 2: XPS-derived surface compositions (atom\%) of the Co$\mathrm{Al}_{2} \mathrm{O}_{3}$ oxides.

\begin{tabular}{lccc}
\hline Sample & $\mathrm{Co} / \mathrm{at} \%$ & $\mathrm{Al} / \mathrm{at} \%$ & sat1/Co $2 \mathrm{p}_{3 / 2}{ }^{*}$ \\
\hline $5 \mathrm{Co} / \mathrm{Al}_{2} \mathrm{O}_{3}(973)$ & 0.5 & 41.8 & 0.9 \\
$10 \mathrm{Co} / \mathrm{Al}_{2} \mathrm{O}_{3}(973)$ & 0.9 & 43.1 & 0.8 \\
$15 \mathrm{Co} / \mathrm{Al}_{2} \mathrm{O}_{3}(973)$ & 1.0 & 42.3 & 0.7 \\
\hline
\end{tabular}

$x \mathrm{Co} / \mathrm{Al}_{2} \mathrm{O}_{3}(y)=$ cobalt loading $(w t \%)$ on $\mathrm{Al}_{2} \mathrm{O}_{3}$ (calcination temperature, $\mathrm{K})$.

*Area ratios from the Co $2 \mathrm{p}$ region spectra.

with those reported for $\mathrm{Co}$ in the $\mathrm{CoAl}_{2} \mathrm{O}_{4}$ spinel structure $[22,26]$. The surface concentrations in at $\%$ are summarized in Table 2.

Figure 7 shows the Co surface atomic concentration (left axis) and the sat1/Co $2 \mathrm{p}_{3 / 2}$ area ratio (right axis) as a function of the Co loading. Comparing the atomic surface concentrations of Co with the respective sat1/Co $2 \mathrm{p}_{3 / 2}$ area ratios, opposite trends are observed as a function of the Co loading. When the bulk Co loading is increasing from 5 to $10 \mathrm{wt} \%$, the total Co atomic surface concentration increases from $0.50 \%$ to $0.94 \%$ indicating that the surface atomic concentration changes at about the same proportion as the bulk concentration. However, further addition of Co does not change the surface composition. Increasing the Co loading enhances the formation tendency of the pure cobalt oxide phase $\mathrm{Co}_{3} \mathrm{O}_{4}$, which has weak satellite peaks. This oxide with spinel structure is a mixture of two different Co oxidation states with one $\mathrm{Co}^{2+}$ ion in a tetrahedral site and two $\mathrm{Co}^{3+}$ ions in octahedral sites. While the former one is in a highspin state, the second is in a low-spin state and does not lead to a shake-up process [26]. When the XPS area ratio of satl to Co $2 p_{3 / 2}$ is analysed as a function of the Co loading, indeed a decreasing trend is observed. According to these results, it is not possible to rule out the existence of a small amount of $\mathrm{Co}$ in the form of $\mathrm{Co}_{3} \mathrm{O}_{4}$ in the $\mathrm{Co}-\mathrm{Al}_{2} \mathrm{O}_{3}$ samples with high Co loading.

The UHV-FTIR spectra recorded after $\mathrm{CO}$ adsorption on the $5 \mathrm{Co}-\mathrm{Al}_{2} \mathrm{O}_{3}$ sample at $100 \mathrm{~K}$ are presented in Figure 8 . 


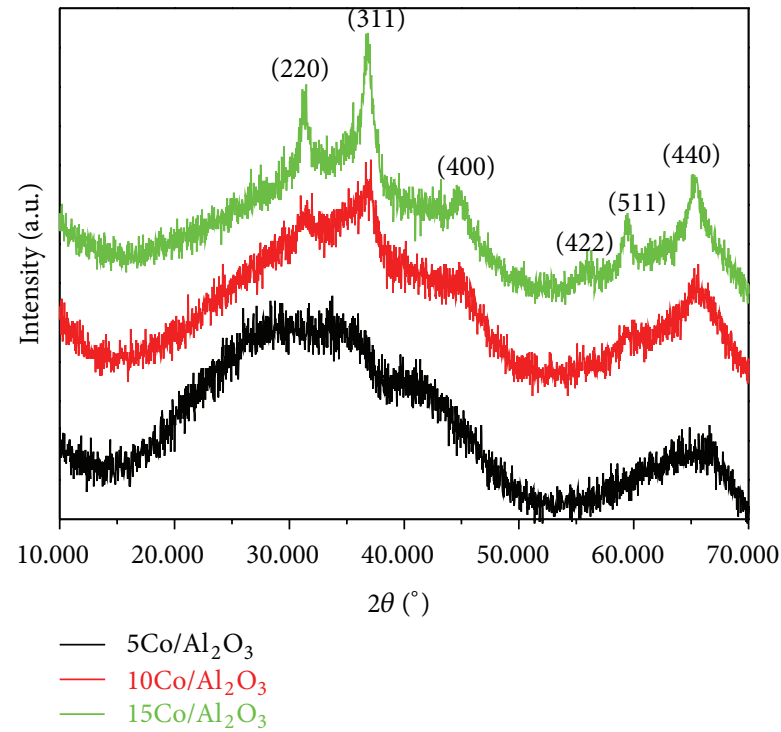

(a)

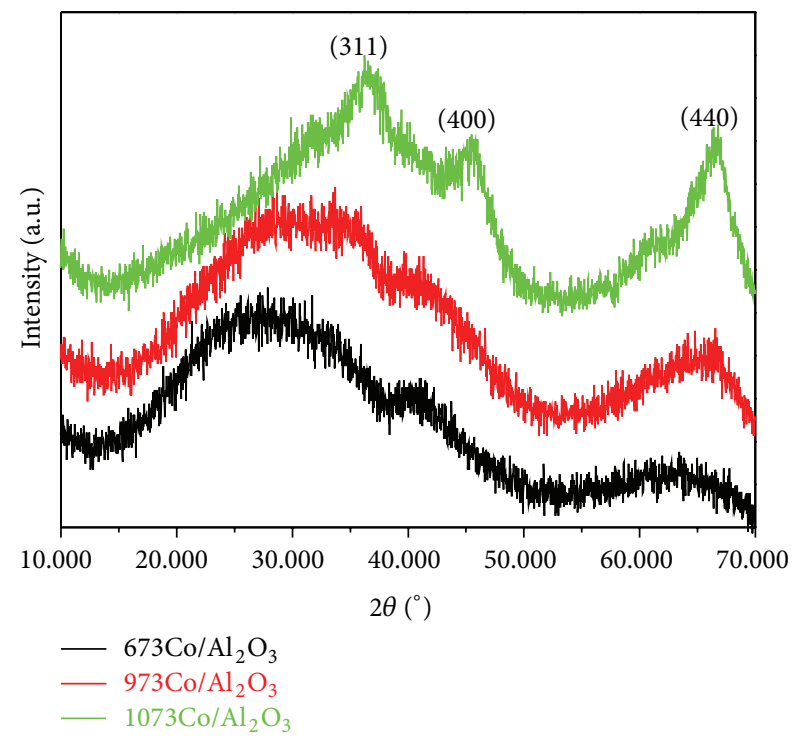

(b)

FIgURE 4: XRD patterns of the $\mathrm{Co}-\mathrm{Al}_{2} \mathrm{O}_{3}$ oxides with (a) different cobalt loadings: (A) $5 \mathrm{wt} \%$, (B) $10 \mathrm{wt} \%$, (C) $15 \mathrm{wt} \%$, and (b) different calcination temperatures: (A) $673 \mathrm{~K},(\mathrm{~B}) 973 \mathrm{~K}$, and (C) $1073 \mathrm{~K}$. The reflections originate from the spinel structure.

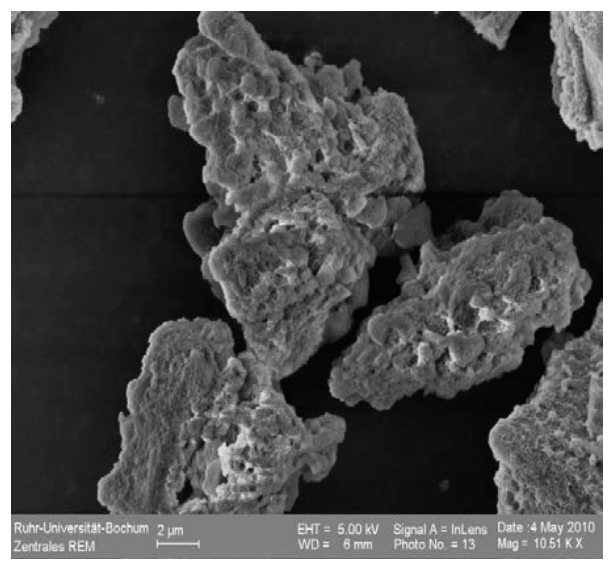

(a)

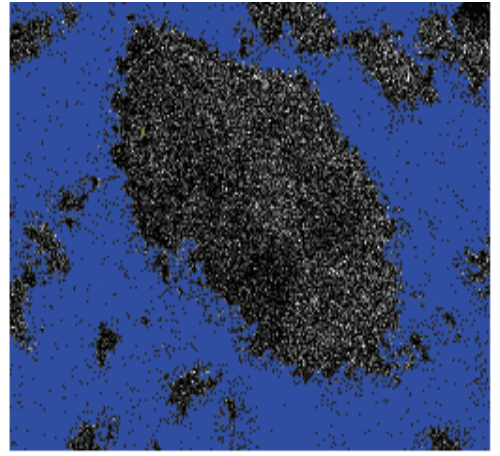

$\mathrm{Al} \mathrm{Ka1}$

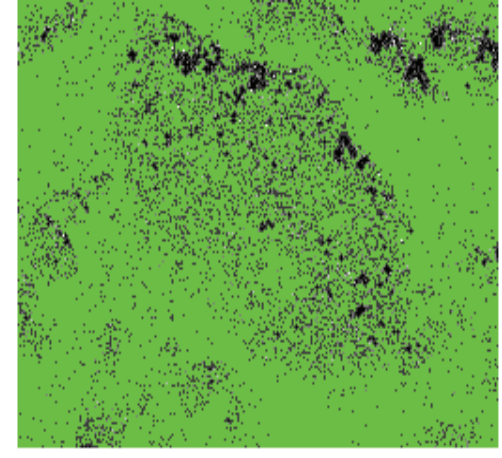

O Kal

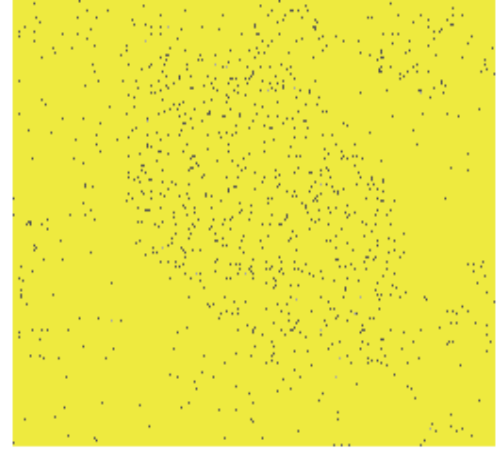

Co Ka1

(b)

FIGURE 5: Representative SEM images (a) and elemental mapping (b) of 5Co- $\mathrm{Al}_{2} \mathrm{O}_{3}$. 


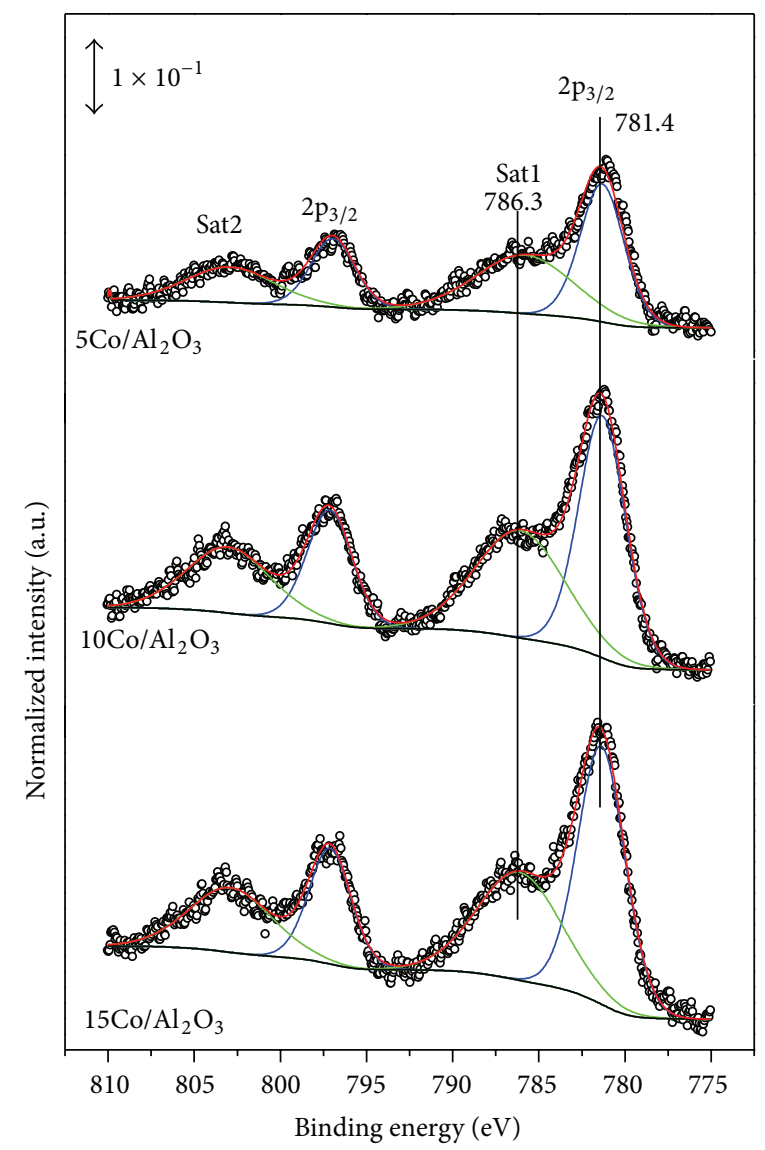

Figure 6: Co 2p XP spectra of the $\mathrm{Co}_{x} \mathrm{O}_{y} / \mathrm{Al}_{2} \mathrm{O}_{3}$ composites with different Co loadings calcined at $973 \mathrm{~K}:$ (A) 5 wt $\%$ Co, (B) 10 wt $\%$ Co, and (C) $15 \mathrm{wt} \% \mathrm{Co}$.

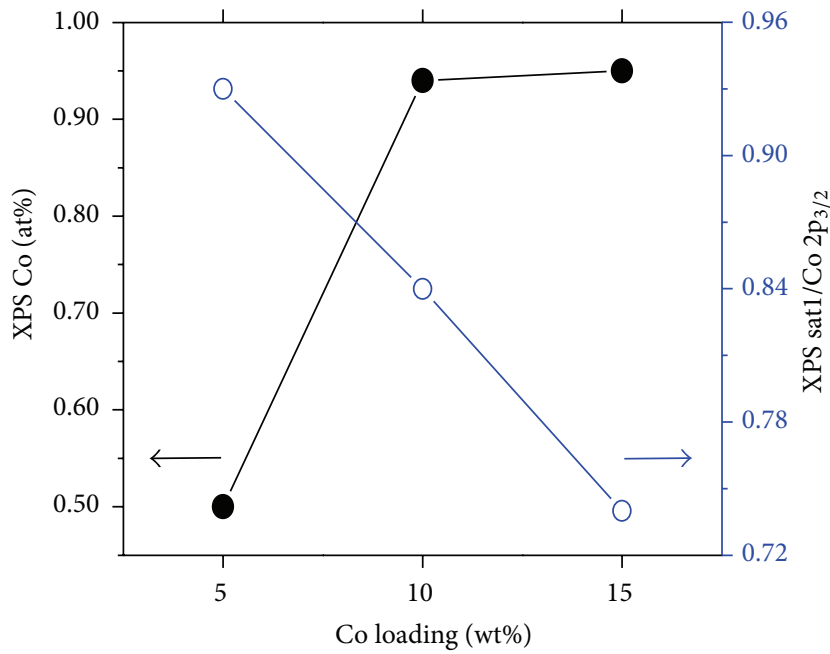

(a)

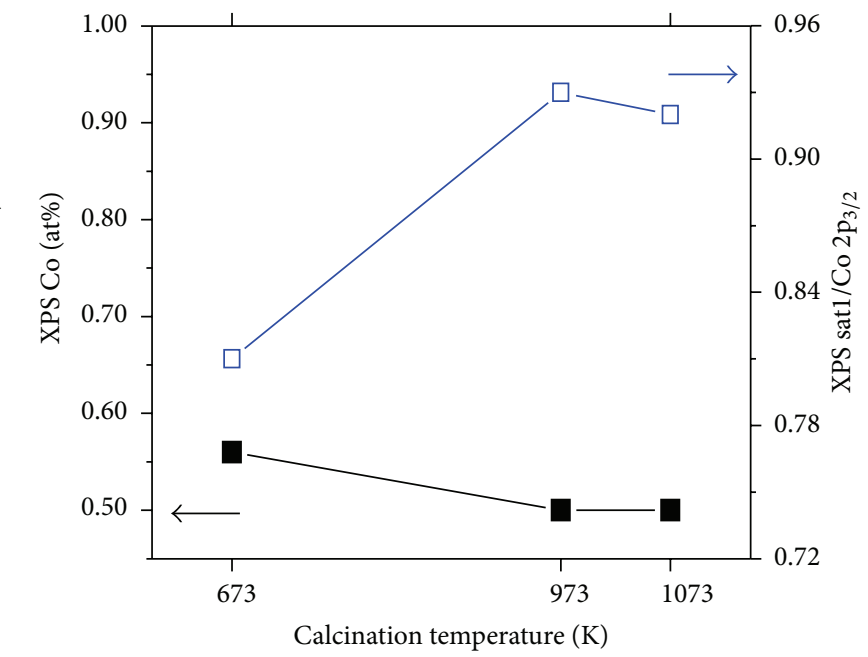

(b)

FIGURE 7: XPS Co atomic concentration (filled circles) and sat1/Co $2 \mathrm{p}_{3 / 2}$ ratio (open circles) of mixed Co- $\mathrm{Al}_{2} \mathrm{O}_{3}$ oxides calcined at $973 \mathrm{~K}$ with different Co loadings. 


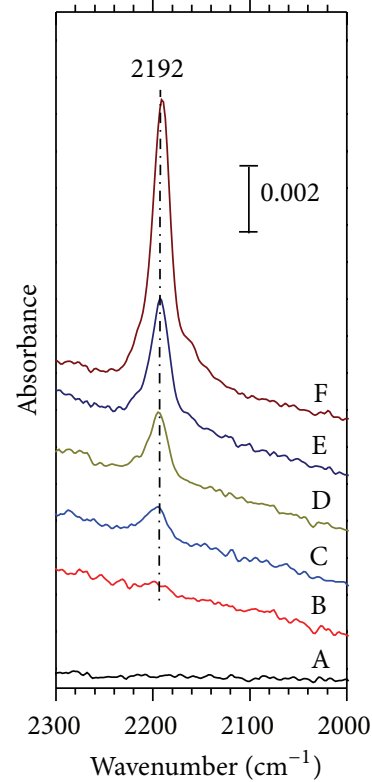

(a)

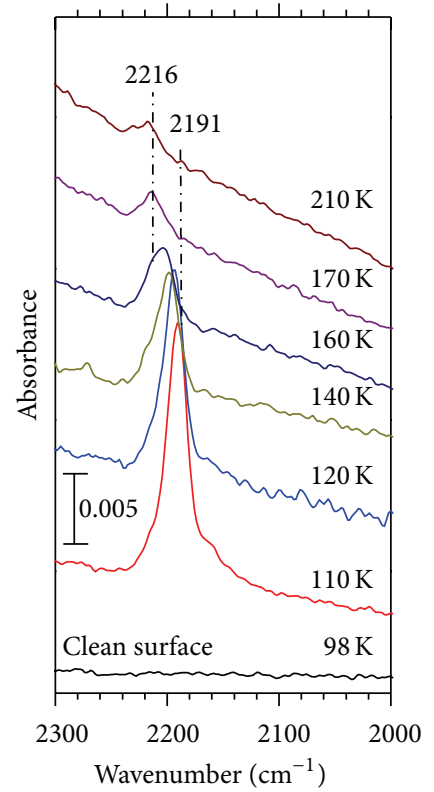

(b)

FIGURE 8: UHV-FTIR spectra obtained after exposing the clean $\mathrm{Co}_{x} \mathrm{O}_{y} / \mathrm{Al}_{2} \mathrm{O}_{3}$ composite to different doses of CO at $100 \mathrm{~K}$ in an UHV chamber; (a) (A) clean surface, (B) $5 \times 10^{-7} \mathrm{mbar}$, (C) $1 \times 10^{-6} \mathrm{mbar}$, (D) $5 \times 10^{-6} \mathrm{mbar}$, (E) $1 \times 10^{-5} \mathrm{mbar}$, (F) $5 \times 10^{-5} \mathrm{mbar}$, and (G) $1 \times 10^{-4} \mathrm{mbar} \mathrm{CO}$; (b) further heating to the indicated temperatures under UHV.

In order to obtain a clean and adsorbate-free surface the sample was pretreated in UHV at $850 \mathrm{~K}$ (Figure $8(\mathrm{a})$ ). After exposing the clean sample to $\mathrm{CO}$ at $100 \mathrm{~K}$, a broad single CO stretching band is observed at $2176 \mathrm{~cm}^{-1}$, which is asymmetric to higher wavenumbers. This band appears at higher wavenumbers compared with the corresponding gas phase CO band $\left(2143 \mathrm{~cm}^{-1}\right)$, which is characteristic for CO adsorption on oxide surfaces. The interaction of $\mathrm{CO}$ with $5 \mathrm{Co}-\mathrm{Al}_{2} \mathrm{O}_{3}$ was further investigated by varying the temperature. Figure 7(b) shows the UHV-FTIR spectra recorded after exposing the clean $\mathrm{Co}-\mathrm{Al}_{2} \mathrm{O}_{3}$ sample to $\mathrm{CO}$ at $100 \mathrm{~K}$ followed by subsequent heating. With increasing temperature the intensity of the $\mathrm{CO}$ band at $2176 \mathrm{~cm}^{-1}$ decreases markedly and almost disappears at around $240 \mathrm{~K}$.

In order to identify the influence of the cobalt ions on CO adsorption, further UHV-FTIR experiments were carried out for a pure mesoporous $\mathrm{Al}_{2} \mathrm{O}_{3}$ sample (Figure 9). After exposing the clean mesoporous $\mathrm{Al}_{2} \mathrm{O}_{3}$ sample to $\mathrm{CO}$ at $110 \mathrm{~K}$, a single $\mathrm{CO}$ stretching band appears at $2192 \mathrm{~cm}^{-1}$. This band is assigned to a $\mathrm{CO}$ species bound to the $\mathrm{Al}^{3+}$ cations of the mesoporous $\mathrm{Al}_{2} \mathrm{O}_{3}$ surface. Figure 8 (b) shows the UHV-FTIR spectra recorded after the sample was heated subsequently to higher temperatures. Upon heating, the intensity of the $\mathrm{CO}$ band at $2192 \mathrm{~cm}^{-1}$ decreases until the band completely disappears at around $210 \mathrm{~K}$. Simultaneously, the band shifts slightly to higher frequencies. The blue shift of the $\mathrm{CO}$ band on mesoporous $\mathrm{Al}_{2} \mathrm{O}_{3}$ is related to the decrease of $\mathrm{CO}$ coverage at higher temperatures, which is in line with the results for $\mathrm{CO}$ adsorption on other oxide surfaces such as $\mathrm{ZnO}$ [27].
In general, the blue shift of the $\mathrm{CO}$ band on both pure mesoporous $\mathrm{Al}_{2} \mathrm{O}_{3}$ and $\mathrm{Co}-\mathrm{Al}_{2} \mathrm{O}_{3}$ with respect to the gas phase value can be explained by both the Stark effect and $5 \sigma$ donation from $\mathrm{CO}$ to the surface cations [23-31]. Importantly, for both the mesoporous $\mathrm{Al}_{2} \mathrm{O}_{3}$ and the $5 \mathrm{Co}-\mathrm{Al}_{2} \mathrm{O}_{3}$ sample only one dominating $\mathrm{CO}$ band was identified. In comparison to the band at $2192 \mathrm{~cm}^{-1}$ for pure alumina, the band observed for $5 \mathrm{Co}-\mathrm{Al}_{2} \mathrm{O}_{3}$ at $2176 \mathrm{~cm}^{-1}$ is clearly shifted. These findings provide further spectroscopic evidence for the incorporation of the $\mathrm{Co}^{2+}$ ions into $\mathrm{Al}_{2} \mathrm{O}_{3}$ during the synthesis instead of a mixture of separated $\mathrm{Co}$ and $\mathrm{Al}$ oxides.

In previous studies, UHV-FTIR has been used to monitor the coadsorption of $\mathrm{CO}$ and $\mathrm{CO}_{2}$ on $\mathrm{ZnO}$ nanoparticles [32]. It was found that the preadsorption of $\mathrm{CO}_{2}$ leads to a slight blue shift of the $\mathrm{C}-\mathrm{O}$ vibrational band. This shift originates from the formation of tridentate carbonate species on the nonpolar $\mathrm{ZnO}(10-10)$ surface, which increases the Lewis acidity of neighboring $\mathrm{Zn}^{2+}$ cations and shifts the $\mathrm{CO}$ band to higher wavenumbers [27]. The reverse scenario was observed for the $\mathrm{Co}-\mathrm{Al}_{2} \mathrm{O}_{3}$ samples. The presence of $\mathrm{Co}^{2+}$ ions in the $\mathrm{Al}_{2} \mathrm{O}_{3}$ structure led to a decrease of the Lewis acidity of the neighboring $\mathrm{Al}^{3+}$ cations resulting in a decrease of the $\mathrm{C}-\mathrm{O}$ stretching band for the mixed $\mathrm{Co}-\mathrm{Al}_{2} \mathrm{O}_{3}$ oxide compared with pure alumina. In addition, the observation of a significantly broader $\mathrm{CO}$ band on $\mathrm{Co}-\mathrm{Al}_{2} \mathrm{O}_{3}$ also implies the adsorption of $\mathrm{CO}$ molecules on different cationic sites. Further investigations are in progress to gain deeper insight into the interaction of $\mathrm{CO}$ with $\mathrm{Co}-\mathrm{Al}_{2} \mathrm{O}_{3}$.

There are ample examples that have been found in current literature for application of mixed oxide for $\mathrm{CO}$ oxidation. The catalytic redox performance was investigated by applying 


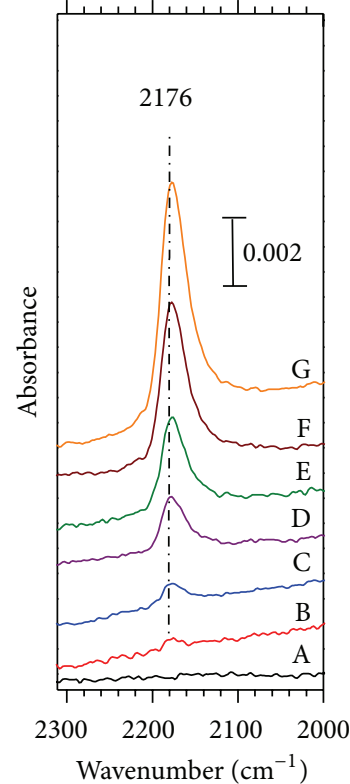

(a)

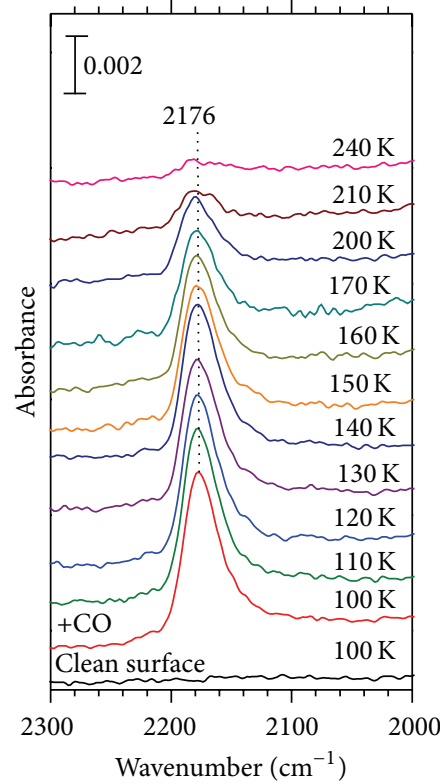

(b)

FIGURE 9: UHV-FTIR spectra obtained after exposing pure $\mathrm{Al}_{2} \mathrm{O}_{3}$ to different doses of $\mathrm{CO}$ at $110 \mathrm{~K}$ in an UHV chamber; (a) (A) clean surface, (B) $1 \times 10^{-6}$ mbar, (C) $5 \times 10^{-6} \mathrm{mbar}$, (D) $1 \times 10^{-5} \mathrm{mbar}$, (E) $5 \times 10^{-5} \mathrm{mbar}$, and (F) $1 \times 10^{-4} \mathrm{mbar}$ CO; (b) further heating to the indicated temperatures under UHV.

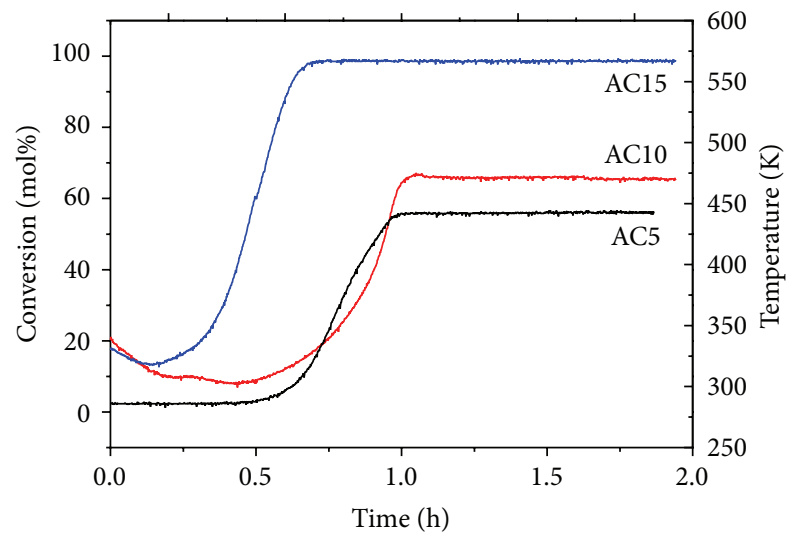

Figure 10: $\mathrm{CO}$ oxidation over the $\mathrm{Co}-\mathrm{Al}_{2} \mathrm{O}_{3}$ composites calcined at $973 \mathrm{~K}$ as a function of the Co loading.

the mesoporous mixed oxides in CO oxidation. The results are shown in Figure 10. Prior to reaction, the samples were reduced in $2 \% \mathrm{H}_{2}$ at $573 \mathrm{~K}$. It is evident from the results that all the samples exhibited good $\mathrm{CO}$ oxidation activity, which strongly increases with increasing Co loadings. The sample $15 \mathrm{Co}-\mathrm{Al}_{2} \mathrm{O}_{3}$ reaches full conversion already at about $450 \mathrm{~K}$. At $573 \mathrm{~K}$, the degree of conversion of the catalysts remains stable for $1 \mathrm{~h}$ time on stream. Cao et al. reported copper catalyst supported by ceria-zirconia and iron. The most active catalyst they observed $25 \%$ of $\mathrm{CuO}$ on ceriazirconia and $15-20 \%$ of $\mathrm{CuO}$ on iron support [27, 32]; moreover, the report demonstrates that both the supports are active for CO oxidation without copper. We are using nearly an inert support alumina compared with highly active not only used as support but also used catalyst phase $\mathrm{Fe}_{2} \mathrm{O}_{3}$ and $\mathrm{Ce} 0.8 \mathrm{Zr} 0.2 \mathrm{O}_{2}$. Moreover, we are using low amount of cobalt $5-15 \%$ age compared with $20-30 \%$ age of copper. These results demonstrate that EISA is a promising synthetic approach for catalytic applications.

\section{Conclusions}

A simple and reproducible synthesis of mesoporous mixed cobalt aluminum oxides with well-ordered pore structure in a single-step approach has been successfully demonstrated for Co contents in the range from 5 to $15 \mathrm{wt} \%$. The cobalt ions were found to be homogeneously dispersed in a poorly crystalline $\mathrm{Al}_{2} \mathrm{O}_{3}$ matrix. The surface areas and the TEM results reflect the well-ordered mesoporosity of the mixed Co- $\mathrm{Al}_{2} \mathrm{O}_{3}$ oxides. XPS and UHV-FTIR CO adsorption studies reveal the presence of $\mathrm{CoAl}_{2} \mathrm{O}_{4}$-like surface species for samples with low Co loading. The red shift of the $\mathrm{CO}$ band relative to pure $\mathrm{Al}_{2} \mathrm{O}_{3}$ indicates a decrease of the surface Lewis acidity due to the presence of the $\mathrm{Co}^{2+}$ cations. The catalytic $\mathrm{CO}$ oxidation activity was found to increase with the Co loading. For the catalyst with a Co loading of $15 \mathrm{wt} \%, 50 \%$ CO conversion was reached at $429 \mathrm{~K}$.

\section{Conflict of Interests}

The authors declare that there is no conflict of interests regarding the publication of this paper.

\section{Acknowledgment}

Ankur Bordoloi thanks the Alexander von Humboldt Foundation for supplying a grant. 


\section{References}

[1] S. Rezgui and B. C. Gates, "Sol-gel synthesis of alumina in the presence of acetic acid: distinguishing gels and gelatinous precipitates by NMR spectroscopy," Chemistry of Materials, vol. 6, no. 12, pp. 2386-2389, 1994.

[2] S. Rezgui, B. C. Gates, S. L. Burkett, and M. E. Davis, "Chemistry of sol-gel synthesis of aluminum oxides with in situ water formation: control of the morphology and texture," Chemistry of Materials, vol. 6, no. 12, pp. 2390-2397, 1994.

[3] F. Vaudry, S. Khodabandeh, and M. E. Davis, "Synthesis of pure alumina mesoporous materials," Chemistry of Materials, vol. 8, no. 7, pp. 1451-1464, 1996.

[4] E. Elaloui, A. C. Pierre, and G. M. Pajonk, "Influence of the solgel processing method on the structure and the porous texture of nondoped aluminas," Journal of Catalysis, vol. 166, no. 2, pp. 340-346, 1997.

[5] C. Marquez-Alvarez, N. Zilkova, J. Perez-Pariente, and J. Cejka, "Synthesis, characterization and catalytic applications of organized mesoporous aluminas," Catalysis Reviews: Science and Engineering, vol. 50, no. 2, pp. 222-286, 2008.

[6] J. Čejka, "Organized mesoporous alumina: synthesis, structure and potential in catalysis," Applied Catalysis A: General, vol. 254, no. 2, pp. 327-338, 2003.

[7] J. T. Pinnavaia, R. Z. Zhang, and R. W. Hicks, "An overview of mesostructured forms of alumina with crystalline framework walls," Studies in Surface Science and Catalysis, vol. 156, pp. 1-10, 2005.

[8] X. S. Fang, C. H. Ye, X. X. Xu, T. Xie, Y. C. Wu, and L. D. Zhang, "Synthesis and photoluminescence of $\alpha-\mathrm{Al}_{2} \mathrm{O}_{3}$ nanowires," Journal of Physics: Condensed Matter, vol. 16, p. 4157, 2004.

[9] R. H. Zhao, C. P. Li, F. Guo, and J. F. Chen, "Scale-up preparation of organized mesoporous alumina in a rotating packed bed," Industrial \& Engineering Chemistry Research, vol. 46, pp. 33173320, 2007.

[10] T. M. Zima, N. I. Baklanova, and N. Z. Lyakhov, "Mesoporous structure of $\mathrm{Al}_{2} \mathrm{O}_{3}$ prepared from poly( $N$-vinylpyrrolidone)modified sols of hydrous metal oxides," Inorganic Materials, vol. 44, no. 2, pp. 146-153, 2008.

[11] P. Yang, D. Zhao, D. I. Margolese, B. F. Chmelka, and G. D. Stucky, "Generalized syntheses of large-pore mesoporous metal oxides with semicrystalline frameworks," Nature, vol. 396, no. 6707, pp. 152-155, 1998.

[12] K. Niesz, P. Yang, and G. A. Somorjai, "Sol-gel synthesis of ordered mesoporous alumina," Chemical Communications, no. 15, pp. 1986-1987, 2005.

[13] Z. Zhang and T. J. Pinnavaia, "Mesostructured $\gamma-\mathrm{Al}_{2} \mathrm{O}_{3}$ with a lathlike framework morphology," Journal of the American Chemical Society, vol. 124, no. 41, pp. 12294-12301, 2002.

[14] S. M. Morris, P. F. Fulvio, and M. Jaroniec, "Ordered mesoporous alumina-supported metal oxides," Journal of the American Chemical Society, vol. 130, no. 45, pp. 15210-15216, 2008.

[15] Q. Yuan, A. X. Yin, C. Luo et al., "Facile synthesis for ordered mesoporous $\gamma$-aluminas with high thermal stability," Journal of the American Chemical Society, vol. 130, no. 11, pp. 3465-3472, 2008.

[16] M. Kuemmel, D. Grosso, C. Boissière et al., “Thermally stable nanocrystalline $\gamma$-alumina layers with highly ordered 3D mesoporosity," Angewandte Chemie, vol. 44, no. 29, pp. 4589-4592, 2005.
[17] Q. Liu, A. Wang, X. Wang, and T. Zhang, "Ordered crystalline alumina molecular sieves synthesized via a nanocasting route," Chemistry of Materials, vol. 18, no. 22, pp. 5153-5155, 2006.

[18] T.-Z. Ren, Z.-Y. Yuan, and B.-L. Su, "Microwave-assisted preparation of hierarchical mesoporous-macroporous boehmite $\mathrm{AlOOH}$ and $\gamma-\mathrm{Al}_{2} \mathrm{O}_{3}$," Langmuir, vol. 20, no. 4, pp. 1531-1534, 2004.

[19] C. T. Kresge, M. E. Leonowicz, W. J. Roth, J. C. Vartuli, and J. S. Beck, "Ordered mesoporous molecular sieves synthesized by a liquid-crystal template mechanism," Nature, vol. 359, no. 6397, pp. 710-712, 1992.

[20] G. J. D. A. A. Soler-Illia, C. Sanchez, B. Lebeau, and J. Patarin, "Chemical strategies to design textured materials: from microporous and mesoporous oxides to nanonetworks and hierarchical structures," Journal of Chemical Reviews, vol. 102, no. 11, pp. 4093-4138, 2002.

[21] D. Grosso, F. Cagnol, G. J. D. A. A. Soler-Illia et al., "Fundamentals of mesostructuring through evaporation-induced selfassembly," Advanced Functional Materials, vol. 14, no. 4, pp. 309-322, 2004.

[22] N. Fairley, CasaXPS Version 2.3.15, Copyright 1999-2009, Casa Software, 1999.

[23] H. Noei, H. Qiu, Y. Wang, M. Muhler, and C. Wöll, "Hydrogen loading of oxide powder particles: a transmission ir study for the case of zinc oxide," ChemPhysChem, vol. 11, no. 17, pp. 3604$3607,2010$.

[24] Y. Wang, A. Glenz, M. Muhler, and C. Wöll, "A new dualpurpose ultrahigh vacuum infrared spectroscopy apparatus optimized for grazing-incidence reflection as well as for transmission geometries," Review of Scientific Instruments, vol. 80, no. 11, Article ID 113108, 2009.

[25] M. Zayat and D. Levy, "Blue $\mathrm{CoAl}_{2} \mathrm{O}_{4}$ particles prepared by the sol-gel and citrate-gel methods," Chemistry of Materials, vol. 12, no. 9, pp. 2763-2769, 2000.

[26] M. Oku and K. Hirokawa, "X-ray photoelectron spectroscopy of $\mathrm{Co}_{3} \mathrm{O}_{4}, \mathrm{Fe}_{3} \mathrm{O}_{4}, \mathrm{Mn}_{3} \mathrm{O}_{4}$, and related compounds," Journal of Electron Spectroscopy and Related Phenomena, vol. 8, no. 5, pp. 475-481, 1976.

[27] H. Noei, C. Wöll, M. Muhler, and Y. Wang, "The interaction of carbon monoxide with clean and surface-modified zinc oxide nanoparticles: a UHV-FTIRS study," Applied Catalysis A: General, vol. 391, no. 1-2, pp. 31-35, 2011.

[28] A. Zecchina and C. O. Areán, "Diatomic molecular probes for mid-IR studies of zeolites," Chemical Society Reviews, vol. 25, no. 3, pp. 187-197, 1996.

[29] A. B. Anderson and J. A. Nichols, "Relaxation in zinc oxide (10.lovin.10), (0001), and (000.lovin.1) surfaces and the adsorption of carbon monoxide," Journal of the American Chemical Society, vol. 108, no. 7, pp. 1385-1388, 1986.

[30] J. T. Kummer, "Use of noble metals in automobile exhaust catalysts," Journal of Physical Chemistry, vol. 90, no. 20, pp. 4747-4752, 1986.

[31] M. Shelef and R. W. McCabe, "Twenty-five years after introduction of automotive catalysts: what next?" Catalysis Today, vol. 62, no. 1, pp. 35-50, 2000.

[32] J.-L. Cao, Y. Wang, X.-L. Yu, S.-R. Wang, S.-H. Wu, and Z.-Y. Yuan, "Mesoporous $\mathrm{CuO}-\mathrm{Fe}_{2} \mathrm{O}_{3}$ composite catalysts for lowtemperature carbon monoxide oxidation," Applied Catalysis B, vol. 79, pp. 26-34, 2008. 

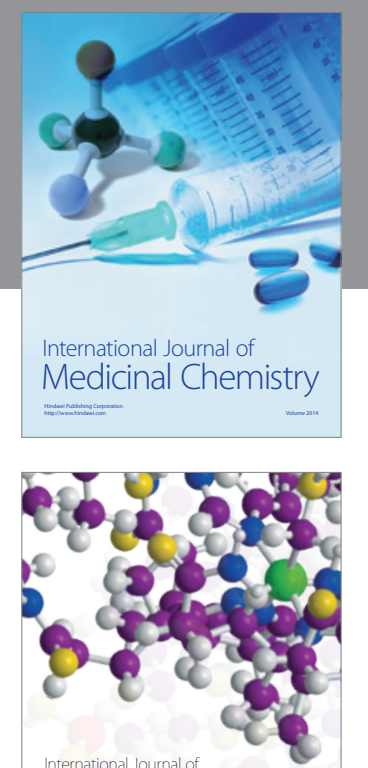

\section{Carbohydrate} Chemistry

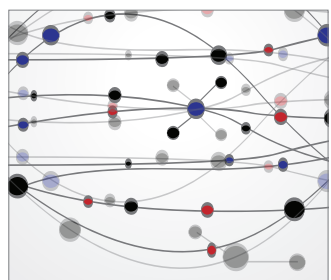

The Scientific World Journal
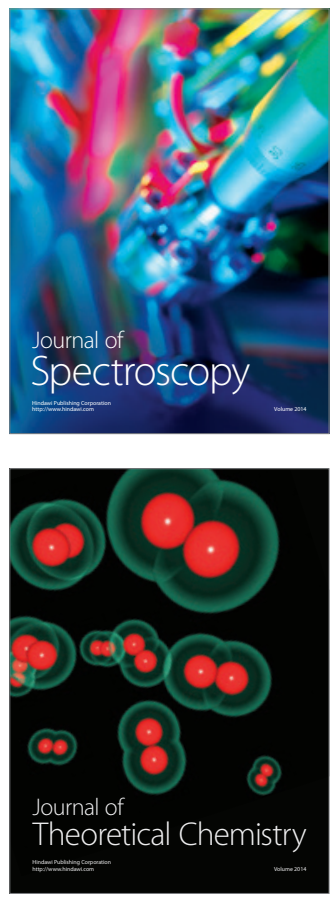
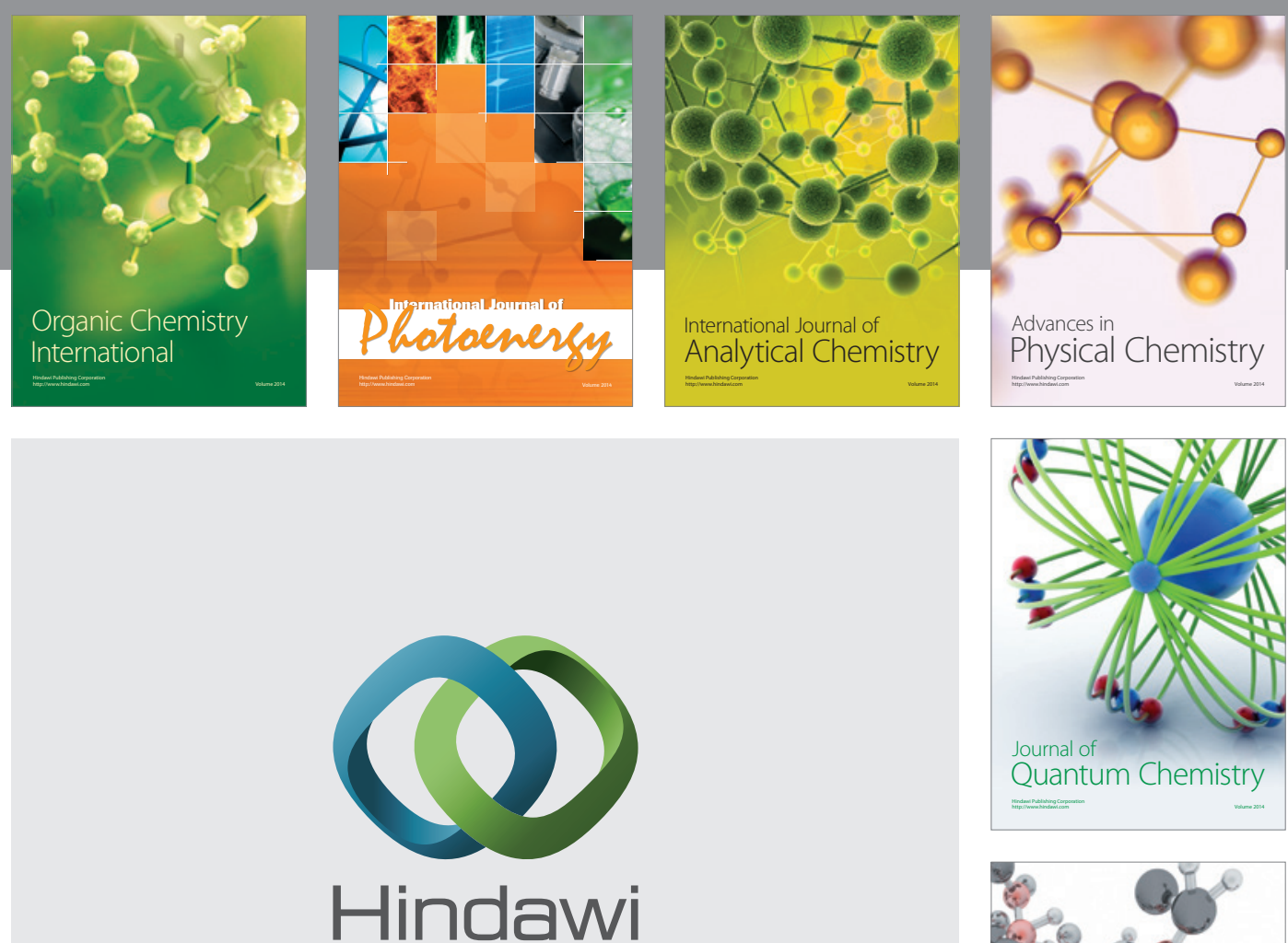

Submit your manuscripts at

http://www.hindawi.com

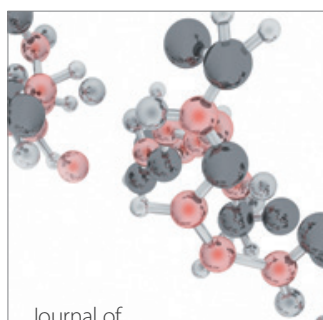

Analytical Methods

in Chemistry

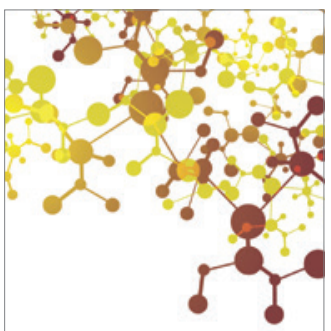

Journal of

Applied Chemistry

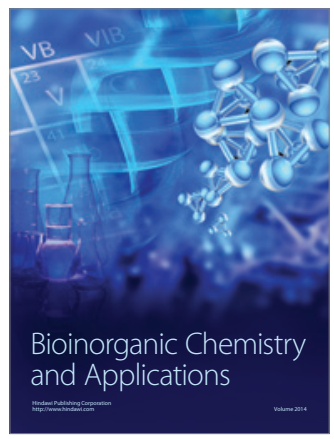

Inorganic Chemistry
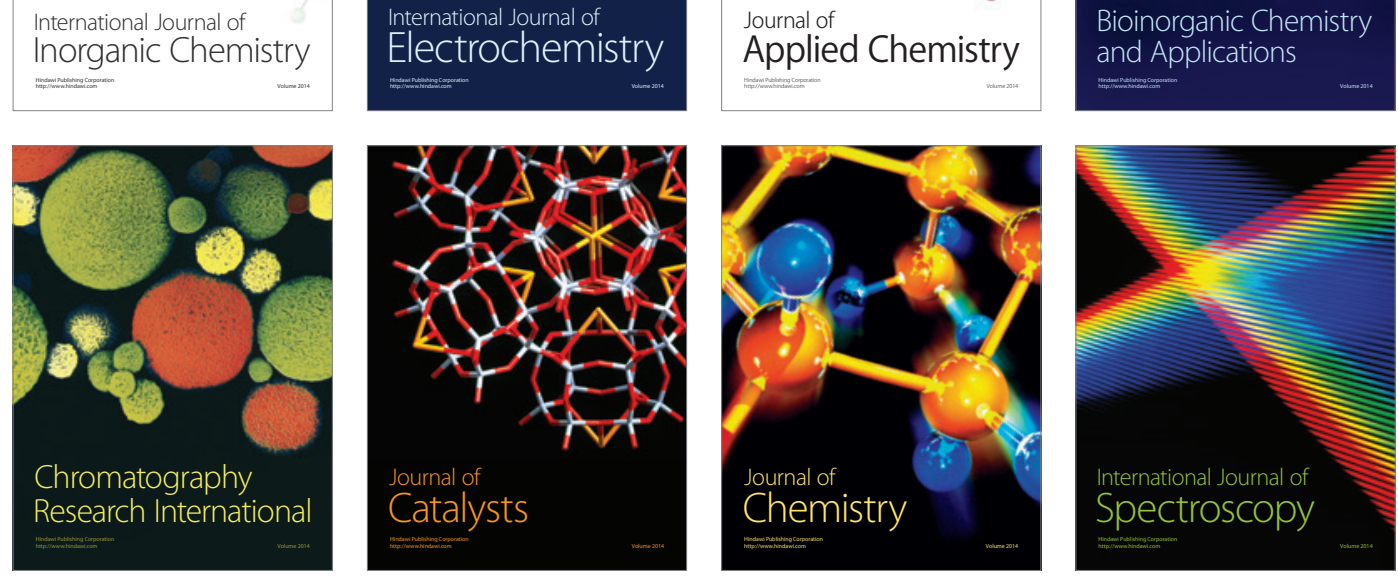